\title{
A Study of Postural Safety and Low-Cost Electromyography (EMG) Device Towards Grocery Workers in Kota Samarahan, Sarawak
}

\author{
Mohd Azrin Mohd Said ${ }^{1,2 *}$, Brian Egan Jackson Tubam ${ }^{1}$, Nor Kamaliana Khamis ${ }^{2}$ and Aishah Arsad ${ }^{3}$ \\ ${ }^{1}$ Department of Mechanical and Manufacturing Engineering, Faculty of Engineering, \\ Universiti Malaysia Sarawak, 94300 Kota Samarahan, Sarawak, Malaysia \\ ${ }^{2}$ Department of Mechanical and Manufacturing Engineering, Faculty of Engineering and Built \\ Environment, Universiti Kebangsaan Malaysia Sarawak, 43600 Bangi, Malaysia \\ ${ }^{3}$ Institut Tadbiran Awam Negara (INTAN) Kampus Sarawak, 94300 Kota Samarahan, \\ Sarawak, Malaysia
}

\begin{abstract}
Body posture is one of the most important parts when lifting an object as it can causes injury if the wrong technique and body posture were used. A worker will injure their low back if a bad posture is not in consideration. A good body posture is recommended among workers to reduce the chance of injury while lifting and improve their postural safety. The main objectives of this study are to observe the body posture of the worker during lifting and study the comparison of using lower back support when lifting. It also investigates the muscle activity of the worker during heavy lifting using EMG and simulates the worker's movement using CATIA Software for Rapid Upper Limb Assessment (RULA) results. The selected grocery was chosen in Kota Samarahan, Sarawak with 7 male respondents are identified to undergo this study. The results show that the worker with lower back support tends to show raw EMG signal with lower muscle activity compared to without using lower back support. Thus, using belt support can reduce muscle activity by up to $67.4 \%$ compare to not wearing back support. Raw EMG signals also show 3010 amplitude (mV) muscle activity if postural safety of the workers improved by following the NIOSH lifting Recommendations.
\end{abstract}

\section{Keywords: Postural Safety, Electromyography, Low-Cost EMG, lower back pain, CATIA, Grocery Workers}

\section{INTRODUCTION}

Low back pain (LBP) is a serious health problem that must be taken care of by personnel. It is very common for a worker to experience symptoms of lower back pain in their working life. This is due to the amount of repetitive work that involves lifting, bending, and awkward position of the body that they must overcome. The worker that encounters lower back pain will contribute impact for the company, family, and government. The total costs of direct medical expenditures and loss of work productivity combined related to low back pain has been estimated to be as high as $\$ 635$ billion annually in the US [1,2]. A lot of expenses must be pay to give treatment to the worker that have low back pain in working their working place.

Furthermore, some company productivity has been decreased due to workers that have to take medical leave due to their lower back pain problem. Lower back pain was the number one symptom complaint express by patient aged 25 to 60 years old and it is the costliest medical problem for the group age 30 to 60 years and it is also the most common health problem among older adults that results in pain and disability [3, 4-8]. Lower back pain has a direct relationship between overweight, duration of the employee working, age, and leisure-time physical activity [9]. There is also research showing that standing without the freedom to sit was associated with also related to LBP issues [9]. Other than that, different occupational physical, and psychosocial were factors also associated with LBP in sitting compared with standing workers [10].

A good postural will lead to the good safety of the workers. This also can prevent and reduce LBP and work musculoskeletal disorder (WMSD) problems among the workers. According to Malaysian's Factories and Machinery Act (1967): Section 12 stated that no person shall be employed to lift, carry, or move any load

*Corresponding Author: Mohd Azrin Mohd Said, Department of Mechanical and Manufacturing Engineering, Faculty of Engineering, Universiti Malaysia Sarawak, 94300 Kota Samarahan, Sarawak, Malaysia, email: msmazrin@unimas.my or $\underline{\text { mohdazrin.unimas@gmail.com }}$ 
so heavy as to be likely to cause bodily injury to themselves [11]. Some research also shows that manual handling is one of the main causes of musculoskeletal injuries in the workplace [12]. Based on Malaysian's Social Security Organisation (Socso) Annual Report (2014), the number of cases of occupational diseases increased from 2005 with 194 cases until 2014 had reached 3002 cases. Apart from that, 675 cases in 2014 were related to occupational musculoskeletal diseases [13].

The main issue for the worker is lifting heavy objects during working which will lead to bodily injury. This problem occurs when lifting heavy objects manually and not by using mechanical means such as forklifts or hand trucks to transport items. A study has been done on the acceptable weight for the human to lift is between, underweight $\left(<18.5 \mathrm{~kg} / \mathrm{m}^{2}\right)$, normal $(18.5-$ $\left.24.9 \mathrm{~kg} / \mathrm{m}^{2}\right)$ and overweight is $\left(>25 \mathrm{~kg} / \mathrm{m}^{2}\right)$ [12]. Furthermore, awkward postures can be the main cause of body injuries for the worker during lifting [12]. By doing Bending and reaching the load that is away from the body it can cause the postural back body to undergo load concentrated more on the back which leads to stress on the lower spine and muscle fatigue [12]. Statistical analysis showed that workers in this study who reported more lifts per work shift were more likely to report instances of low back pain than other workers [14].

Thus, this preliminary study aims to investigate the body posture of grocery workers while doing lifting activities in the workplace. It is also to investigate the difference between using lower back belt support and without lower back belt support in lifting and measure using low-cost develop device electromyography (EMG) and CATIA Software.

\section{METHODOLOGY}

This study is to undergo an experiment by achieving the main objectives that have been list out. The selected methodology was used to study the back pain of the selected grocery workers. To get the best result, several factors needed to be implemented. This is to reduce the error occurring during taking the result. The main aim of this study is to observe the body posture of the worker during lifting and the comparison of using lower back support when lifting. It also investigates the muscle activity of the worker during heavy lifting using EMG and mimics the worker using CATIA Software to get the Rapid Upper Limb Assessment (RULA) results.

\section{Data Collection}

To indicate the worker has experience low back pain before, a set of questionnaires has been done for selected supermarket workers that involve in the lifting process. From the question, the major aim is to determine the age, gender, and duration of work that has more likely to have a low back pain problem. Other factors such as the working environment are also being asked in the questionnaire to determine if this factor will contribute to low back pain.

\section{Video Motion Setup}

A video recording is used in this study to determine the worker's body posture while lifting an object. From the video the analysis, the body posture of the worker by using CATIA software. From the software, we can determine the RULA score analysis of the posture. From observation method and video recording, the analysis of postural safety using CATIA software the RULA results will indicate the critical area which has the most effect on the human body when the wrong technique is used.

\section{Low-Cost Electromyography (EMG) Equipment}

In this study, the low-cost EMG device that has been developed by the researcher was used. For the low-cost EMG device, the equipment that is being used is ESPDuino-32 and Myoware sensor. The ESPDuino-32 board acts as the microcontroller with an integrated WiFi module for the device and the Myoware is acting as a muscle activity sensor data. This device is used to analyze the muscle activity of the worker while using back support and without back support. The data also gather in real-time with the ESPDuino-32 that is connected to a Wi-Fi connection and the data transmitted to the ThingSpeak server as an IoT analytics platform service. From the server, the muscle activity data of the worker will be displayed. A comparison is made from the analyzed data to determine the effect of using back support.

The low-cost smart EMG device that develops is shown in Figure 1. Then this low-cost EMG device was attached to the workers. Figure 2 shows the placement of the device to the worker's back body.

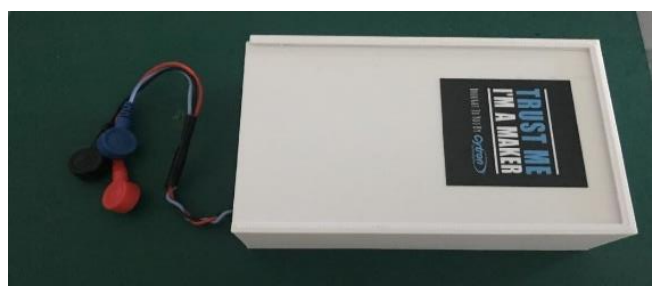

Fig 1: Low-cost EMG Device

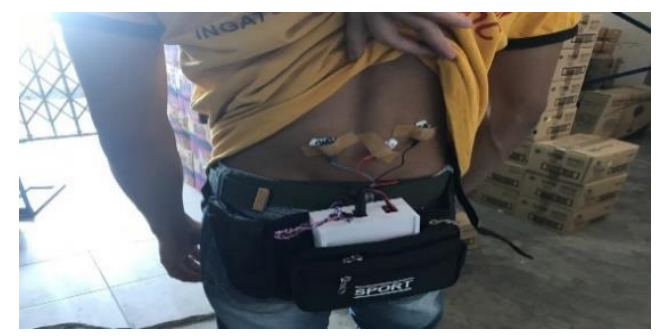

Fig 2: Low-Cost EMG Device on worker back body 


\section{RESULT AND DISCUSSION}

The process of restocking the goods start from unloading it from the lorry and transport the good to the store on the second floor of the building. To restock the goods in the grocery, the same process is involved. Figure 3 shows the worker restocks stored on the second floor of the building.
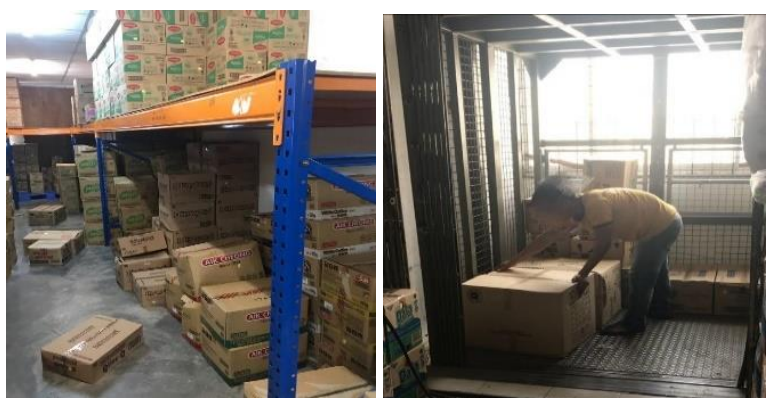

Fig 3: Worker restocks in the grocery store

A total of 7 male respondents with the range age of 20 until 29 years has been participated to contribute to the questionnaire. All the respondents had their own experience with low back pain during lifting objects. Figure 4 shows the weight that has been lifted by the workers every day to restock goods in the supermarket. From Figure 4, about $72 \%$ of the workers carrying or lifting goods weigh between $10-20 \mathrm{~kg}$ per trip. This shows the average weight of the works for the workers to lifting.

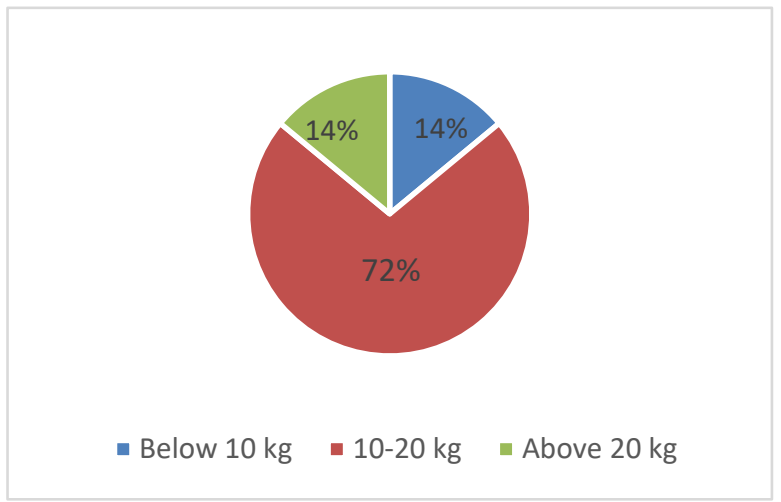

Fig 4: Weightlift by worker

Figure 5 shows the results from Likert scale 1 to 5 (strongly disagree to strongly agree) show the perfective of the worker about back pain in lifting. The average score shows that pain prevents them from lifting the weight off the floors, but they can manage to lift it if the weight is in a convenient position. This shows that the worker needs to use correct posture to lift the weight. Postural safety is one major concern by the workers.

Fig 5: Workers perfective about back pain in lifting

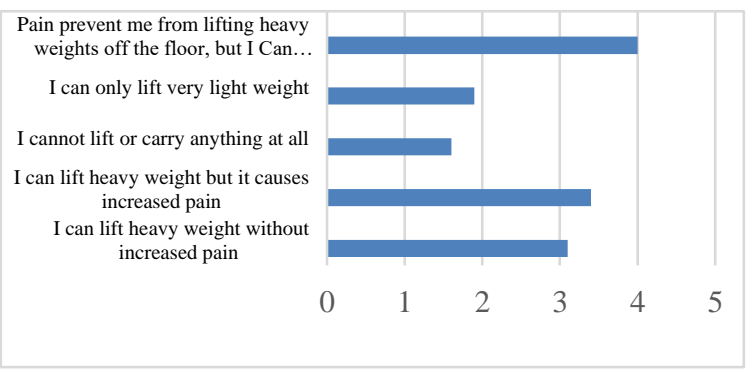

While for low-cost EMG device results, the comparison between without used back support and used back support was discovered. Figure 6 shows the raw EMG signal without the use of back support during lifting. The EMG Signal gathered from real-time data in ThingSpeak. The workers that are being tested have a normal body mass index in this experiment. This result is taken during peak hours of their working task. During peak hours, the staff handle a lot of loading and unloading grocery stock average of $10 \mathrm{~kg}$ to $20 \mathrm{~kg}$ from the store to the shop. Based on the graph, it shows the maximum value of 4600 amplitude $(\mathrm{mV})$ of muscle activity when lifting an object without back support and incorrect body posture.

Fig 6: Raw EMG signal of workers without back

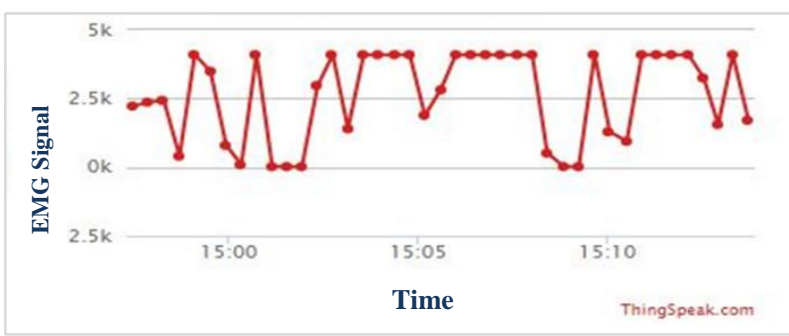

support for loading weight average $10 \mathrm{~kg}-20 \mathrm{~kg}$

Figure 7 shows the raw EMG signal of the same workers but this time by using lower back support. The data show less muscle activity happens when using the belt support. The EMG signal show to be more constant with 1500 amplitude (mV). Thus, using belt support can reduce muscle activity by up to $67.4 \%$ compare to not wearing back support.

Fig 7: Raw EMG signal of workers with back

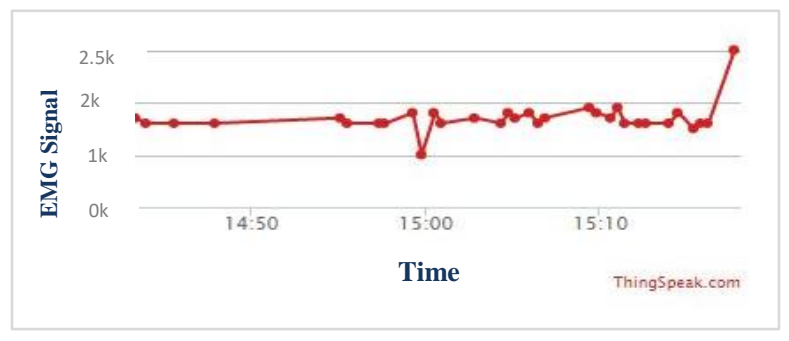

support for loading weight average $10 \mathrm{~kg}-20 \mathrm{~kg}$ 


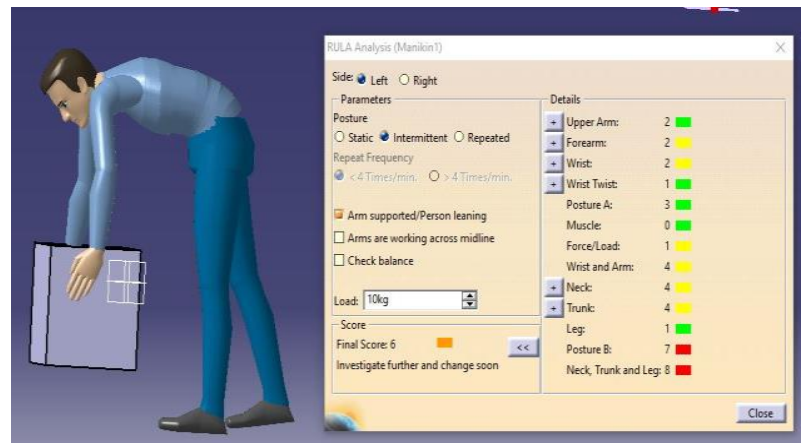

Fig 8: RULA Score for workers lift an object

Based on the video observation of the worker, Figure 8 shows the body posture created in Human Builders with CATIA software. Then the RULA score can be determined to form the current body posture and evaluate with EMG to evaluate the body posture [15]. The final score of the RULA score is 6 which is still a medium risk for the worker. Even though it is a medium risk, but the body posture of lifting needs an improvement for the safety of the worker.

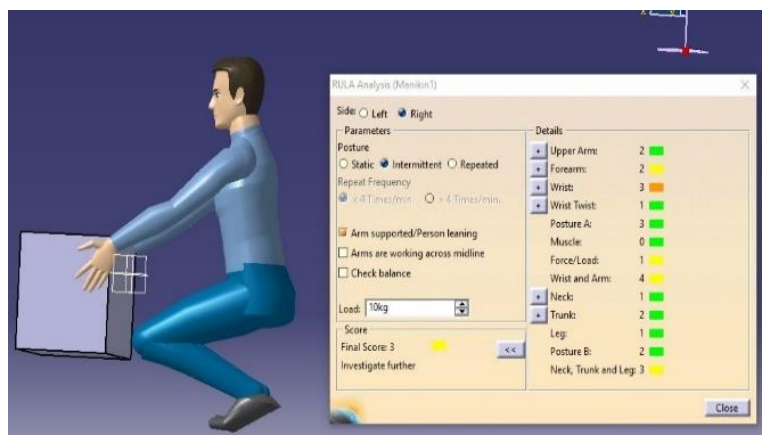

Fig 9: Improve RULA Score for workers

Figure 9 shows the improved body posture of the worker while lifting goods in the store. The correct body posture is needed to reduce back pain and lowered muscle activity. The total improves RULA score is in an acceptable range which is 3 or below 3 for good posture. The differences between improve body posture and bad body posture are that the knee is bend and the back section is in a straight position. This is the acceptable body posture for lifting an object that is lower than knee level. The most affected area of the boy is the wrist only which has a RULA score of 3, where all aspects of body posture in the future need to consider. Other lifting equipment or engineering control and good ergonomic design will help to improve the quality of the comfortable feeling to humans [16].

As for raw EMG signal comparison, Figure 10 shows the differences of electromyography signals between a good posture and a bad posture while lifting.

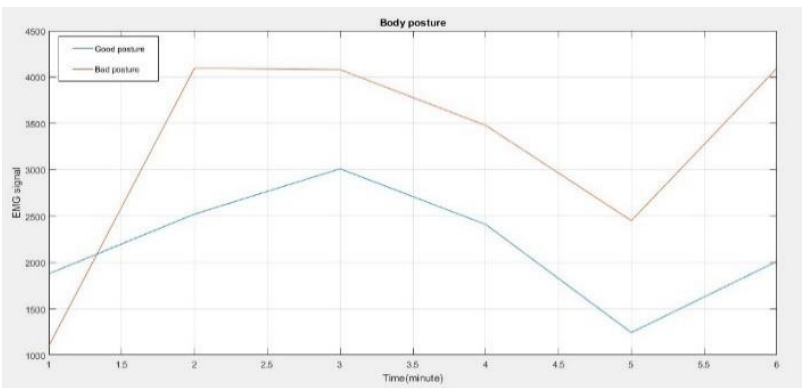

Fig 10: Raw EMG signal for bad and good posture

As the raw EMG signal is the train of Motor Unit Action Potential (MUAP) showing the muscle response to neural stimulation [16]. The amplitude range of the raw EMG signal is $0-10 \mathrm{mV}$ ( +5 to -5 ) before amplification [16]. In this study, the raw EMG signals are not decomposition through MUAP, and noise factors are not included as known that acquires noise while traveling through different tissue [17]. The blue line on the graph represents good body posture and the orange line indicates bad body posture. The peak point of the blue line is 3010 amplitude $(\mathrm{mV})$ and the lowest electromyography signal it reaches is 1243 amplitude $(\mathrm{mV})$. While the orange line, the peak point of the graph is 4095 amplitude $(\mathrm{mV})$ and the lowest point is 2451 amplitude $(\mathrm{mV})$. This shows a difference between good and bad posture and the effect of muscle in lifting. This can help to reduce the back pain of workers if they follow the NIOSH Lifting recommendations [18].

\section{CONCLUSION}

The worker should be aware of their body postural safety and the importance of wearing a kind of lower back support when lifting a heavy object in the workplace. It is important to study the correct body posture as it will prevent injury such as lower back pain to happen. The manager of the grocery store also should give awareness about the importance of body postural safety and provide their worker with lower back support when working. Less injury to the worker will give more benefit to the company as they do not have to pay for the treatment fees. Future research with filtration of EMG Noise signal factors could be studied to investigate the muscle activity of the worker.

\section{ACKNOWLEDGMENTS}

The authors acknowledge the financial support from Osaka Gas Foundation in Cultural Exchange (OGFICE) Research Grant from Japan (IG/F02/OSAKA/02/2018), Many thanks to all the colleagues, undergraduate students from Universiti Malaysia Sarawak (UNIMAS) for assistance and involvement in this research project and to Universiti Kebangsaan Malaysia (UKM) Grant (GUP-2019-019). 


\section{REFERENCES}

[1] Darrell J. Gaskin, Patrick Richard. The Economic Costs of Pain in the United States. The Journal of $\begin{array}{llll}\text { Pain, } 2012 ; & 13 \text { (8): } 715 \quad \text { DOI: }\end{array}$ 10.1016/j.jpain.2012.03.009

[2] Institute of Medicine (US) Committee on Advancing Pain Research C, and Education. Relieving pain in America: a blueprint for transforming prevention. Care, Education, and Research. Washington (DC): The National Academies Press; 2011.

[3] Arnold YL Wong, Jaro Karppinen, Dino Samartzis. Low back pain in older adults: risk factors, management options, and future directions. Scoliosis Spinal Disord. 2017; 12: 14. DOI: 10.1186/s13013-017-0121-3

[4] Bressler HB, Keyes WJ, Rochon PA, Badley E. The prevalence of low back pain in the elderly: a systematic review of the literature. Spine. 1999; 24:1813-9. DOI: 10.1097/00007632-19990901000011

[5] Prince MJ, Wu F, Guo Y, Gutierrez Robledo LM, O'Donnell M, Sullivan R, et al. The burden of disease in older people and implications for health policy and practice. Lancet. 2015; 385:549-62. DOI: $10.1016 / \mathrm{S} 0140-6736(14) 61347-7$

[6] Leveille SG, Guralnik JM, Hochberg M, Hirsch R, Ferrucci L, Langlois J, et al. Low back pain and disability in older women: independent association with difficulty but not inability to perform daily activities. J Gerontol A Biol Sci Med Sci. 1999;54:M487-93.

DOI: 10.1093/gerona/54.10.M487

[7] Reid MC, Williams CS, Gill TM. Back pain and decline in lower extremity physical function among community-dwelling older persons. J Gerontol a Biol Sci Med Sci. 2005; 60:793-7. DOI: 10.1093/gerona/60.6.793

[8] Hoy D, Bain C, Williams G, March L, Brooks P, Blyth F, et al. A systematic review of the global prevalence of low back pain. Arthritis Rheum. 2012; 64:2028-37. DOI: 10.1002/art.34347

[9] Haiou Yang, Scott Haldeman, Ming-Lun Lu, Dean Baker. Low Back Pain Prevalence and Related Workplace Psychosocial Risk Factors: A Study Using Data From the 2010 National Health Interview SurveyJ Manipulative Physiol Ther. 2016 Sep; 39(7): 459-472. DOI: 10.1016/j.jmpt.2016.07.004

[10] Tissot F, Messing K, Stock S. Studying the relationship between low back pain and working postures among those who stand and those who sit most of the working day. Ergonomics. 2009;52(11):1402-1418.
[11] Factory and Machinery Act, (1967). Malaysia: International Law Book Services.

[12] Hamid, A.S \& Tamrin, S.B. (2016). A Proposed Recommended Weight Limit for Lifting Activities Among Young Asian Adults. Human Factors and Ergonomics Journal, Malaysia, Vol 1(1). 62-67.

[13] Social Security Organisation (2014). Social Security Organisation Annual Report. Malaysia.

[14] Schneider, S, Lipinski, S, Schiltenwolf, M. (2006). Occupations associated with a high risk of selfreported back pain: representative outcomes of a back-pain prevalence study in the Federal Republic of Germany. European Spine Journal, 15(6). 821-833. DOI: 10.1007/s00586-005-10152.

[15] Mohd Azrin Mohd Said, Mohd Hasanal Sufri Umar, Nor Kamaliana Khamis, and Aishah Arsad. A Preliminary Study of Postural Safety and LowCost Electromyography (EMG) Towards Logistic Workers in Kuching Sentral. Sci. Int. (Lahore), 32(6),661-665,2020

[16] Mohd Azrin Mohd Said, Bryan Hansen Wennedy, Ahmad Mu'izz Kadir, Abdullah Yassin, M. Shahidul Islam, Syed Tarmizi Syed Shazali, Hishammudin Afifi Huspi, Ahmad Adzlan Fadzli Khairi, Napsiah Ismail. Empirical Study on Ergonomic for Compact Car Seat and Its Effect to Human Posture. Aust. J. Basic \& Appl. Sci., 9(32): 299-304, 2015

[17] M.B.I. Raez, M.S. Hussain, F. Mohd-Yasin. Techniques of EMG signal analysis: detection, processing, classification, and applications. Biol Proced Online. 2006. DOI: 10.1251/bpo115

[18] NIOSH Lifting Recommendations. Retrieved in September $2020 . \quad$ Website: https://www.osha.gov/SLTC/etools/poultry/additi onal_material/niosh.html 